\title{
Social skills and well-being among family caregivers to patients with Alzheimer's disease
}

\author{
Flávia Araujo de Amorim¹,2, Mariana de Campos Pereira Giorgion³, Orestes Vicente Forlenza² \\ ${ }^{1}$ Faculty of Medicine, Federal University of Rio Grande do Sul (UFRGS), Porto Alegre, RS, Brazil. \\ 2 Laboratory of Neurosciences (LIM-27), Institute of Psychiatry, Clinical Hospital, Faculty of Medicine, University of Sao Paulo (HCFMUSP), Sao Paulo, SP, Brazil. \\ 3 Faculty of Education, University of São Paulo (USP), Sao Paulo, SP, Brazil.
}

Institution where the study was conducted: Institute of Psychiatry, Faculty of Medicine, University of São Paulo, São Paulo, SP, Brazil.

Received: 01/26/2017 - Accepted: 10/14/2017

DOl: 10.1590/0101-60830000000143

\begin{abstract}
Background: Caring for a demented relative is frequently associated with burden; yet, a subset of family caregivers may experience it as rewarding. Certain characteristics, including personality factors, may render caregivers more resilient to stress and therefore attenuate the perception of burden and its impact on quality of life. Objective: To determine the association between social skills and well being among family caregivers to patients with dementia. Methods: Forty-one family caregivers to patients with dementia due to Alzheimer's disease (AD) were assessed with Social Skills Inventory (SSI-Del-Prette) and the Zarit Burden Interview; quality of life was estimated with WHO-QoL-bref questionnaire. Results: We found positive correlations between total SSI scores and the psychological $(r=0.450 ; \mathrm{p}=0.003)$ and environmental $(\mathrm{r}=0.408 ; \mathrm{p}=0.008)$ domains of WHO-QoL-bref. The SSI factor 'self-control of aggressiveness' (SSI-F5) was negatively correlated with the magnitude of caregiver burden $(r=-0.483 ; p=0.001)$ and positively associated with the psychological domain of WHO-QoL-bref $(r=0.446 ; p=0.003)$. Caregivers with better 'self-assertion in the expression of positive affect' (SSI-F2) also had better 'social relationships' according to WHO-QoL-bref $(\mathrm{r}=0.402 ; \mathrm{p}=0.009)$. Discussion: The availability of more sophisticated repertoires of social skills may render family caregivers more resilient to burden, preserving their quality of life while enduring this task.
\end{abstract}

Amorim FA et al. / Arch Clin Psychiatry. 2017;44(6):159-61

Keywords: Dementia, Alzheimer's disease, caregiver, burden, social skills.

\section{Introduction}

About $80 \%$ of the amount of care required by demented patients, particularly those with Alzheimer's disease (AD), is provided by persons from their own households ${ }^{1}$. In families, the role of primary caregiver tends to be assigned (often involuntarily) to the spouse or children of the patient ${ }^{1,2}$. Given the highly demanding nature of this role, family caregivers may be overwhelmed by the responsibilities associated with their caring routine, which often precludes their availability to spend time at work, leisure, etc. Therefore, they are prone to experience emotional and physical distress, and often develop burnout syndromes and other stress-related physical and psychological disorders ${ }^{1}$. Furthermore, cut back hours from work (in addition to caregiving being an unpaid job) usually imply financial difficulties to these individuals ${ }^{3,4}$.

Yet, caring for a loved one can be a very rewarding experience, at least for a subset of caregivers 3 . Such positive attitude may rely on the availability of adequate material assets and good coping abilities - which ultimately depends on the caregiver's emotional state and personality characteristics $1,3,4$.

Given that the psychological state of the caregivers affects patient's well being ${ }^{4}$, it is important to examine the variables that influence caregiver's ability to care for a demented person, to deal with pressure, and to manage all the resources required to handle the demands of this task. Here we hypothesize that caregivers' social skills compose the range of key abilities that might be determinant of a good or poor adaptation to this complex role.

Social Skills are related to the competence by which an individual understands its own emotions in order to discern them and use them to guide its own behavior - thus forming a real and true view of itself, and to the competence used by an individual to understand the other, recognizing other's "emotions, moods, temperaments, motivations and intentions", assuring more effective social interactions ${ }^{5}$.

\section{Objectives}

We aimed to investigate whether there is a correlation between objective measures of social skills and self-reported levels of burden and quality of life among family caregivers of $\mathrm{AD}$ patients.

\section{Methods}

The study was conducted at the psychogeriatric clinic of a tertiary hospital in Sao Paulo, Brazil (Institute of Psychiatry, University of Sao Paulo). It was designed to recruit and assess a representative sample of family caregivers to patients with dementia due to AD. The latter were regular outpatients attending this service, subsuming the provision of appropriate diagnosis and treatment by the hospital staff. Caregiver eligibility was defined by the following inclusion criteria: (a) not being paid for to provide care to a patient with $\mathrm{AD}$; (b) being the only or main person to undertake this role; (c) having kinship with the patient; and (d) not having previous history of major psychiatric disorders prior to the diagnosis of dementia in the family member (particularly mood, anxiety, psychotic, and substance userelated disorders). We approached all the eligible family caregivers to $\mathrm{AD}$ patients in the clinic between January and December 2014. All participants signed an informed consent and the study was approved by the local Ethics Committee (CAPPesq). The sample was composed by 41 adults (mean age 61.09 years, ranging from 40 to 80 , and predominantly $50-60$ years of age), mostly women $(87.8 \%$; $\mathrm{n}=36$ ) with medium to higher education level ('complete high school' or 'complete higher education' were respectively $34.14 \%$ and $46.34 \%)$. Caregivers were generally children $(56.09 \% ; n=23$ ) or spouses of patients $(34.14 \% ; \mathrm{n}=14)$. The majority of the respondents was married $(53.65 \% ; n=22)$, lived in the same household as the patient $(90.24 \% ; \mathrm{n}=37)$ and did not have other occupations $(65.85 \%$; $\mathrm{n}=27$ ). The reported family income in Brazilian Real was equivalent 
to $\$ 250$ to $\$ 1,500$ US dollars per month (mean $\$ 750$ ). Caregivers had already performed this task for a mean period of 4.8 years before assessment (ranging from 1 to 7 years), and the average amount of time spent daily in activities related to care was approximately 16 hours. Approximately half of the participants received instrumental help to care.

Participants were interviewed by a trained researcher (F.A.A.). The Social Skills Inventory (SSI-Del-Prette) ${ }^{6}$ was used to assess caregivers' repertoires of social skills. The SSI-Del-Prette is one of the most used instruments in Brazil to assess social skills, with valid internal consistency, stability and reliability ${ }^{7}$. The total score may be subdivided into five factors: F1, coping and self-assertion with risk; $\mathrm{F} 2$, self-assertion in the expression of positive affect; F3, conversation and social confidence; F4, self-exposure to unknown people and new situations; and F5, self-control of aggressiveness ${ }^{6}$.

Caregivers' well being was assessed through their perceptions about quality of life (QoL) and burden. QoL may be defined as an individual's perception of their position in life in the context of culture and value systems in which they live and in relation to their goals, expectations, standards and concerns ${ }^{8}$. QoL was estimated by the Brazilian Portuguese version of WHO-QoL-bref ${ }^{9}$, an instrument developed by the World Health Organization with 26 items divided into four domains: physical, psychological, social relationships and environment. The calculation and correction of scores were made according to Pedroso et al. ${ }^{10}$.

Caregiver burden was assessed through the Brazilian version of Zarit Burden Interview (ZBI) ${ }^{11,12}$. It covers the relationship between caregiver and patient, caregiver health conditions, psychological well-being, financial condition and interpersonal relationships ${ }^{4}$. Total scores $(0-88)$ are obtained by the sum of the scores in each item $(0-4)$ of the test.
Pearson's correlations were used to determine the association between variables, namely well-being parameters (QoL and burden) and social skill repertoires. The strength of the correlations were defined according to Ricardo et al. ${ }^{13}$, i.e., strong, moderate and weak correlations defined by Pearson's test values of 0.7-1.0, 0.30.7 and $0-0.3$ respectively. Student's $t$ tests were used to compare means of normally distributed numeric variables, and the statistical significance was set at $5 \%$. The SPSS software (IBM) was used for the statistical analysis.

\section{Results}

Table 1 shows positive moderate correlations between the total score of SSI-Del-Prette and: a) the total score of WHO-QoL-bref $(\mathrm{r}=0.397 ; \mathrm{p}=0.01) ; \mathrm{b})$ the psychological domain of WHO-QoL-bref $(\mathrm{r}=0.450 ; \mathrm{p}=0.003) ; \mathrm{c})$ the environmental domain of WHO-QoL$\operatorname{bref}(\mathrm{r}=0.408 ; \mathrm{p}=0.008)$.

With respect to the distinct factor of the SSI-Del-Prette schedule, we also found a moderate positive correlation between Factor 2 ('self-assertion in the expression of positive affect') and several items of the WHO-QoL-bref, i.e.: total score $(\mathrm{r}=0.363 ; \mathrm{p}=$ $0.02)$; psychological domain $(\mathrm{r}=0.351 ; \mathrm{p}=0.024)$; social relations domain $(r=0.402 ; \mathrm{p}=0.009)$; environmental domain $(\mathrm{r}=0.308$; $\mathrm{p}=0,05)$. The latter domain was also moderately correlated with Factor 3 of SSI-Del-Prette ('conversation and social confidence') $(\mathrm{r}=0.321 ; \mathrm{p}=0.041)$.

Caregiver burden was negatively correlated with 'self-control of aggressiveness' (Factor 5 of SSI-Del-Prette) $(r=-0.483 ; \mathrm{p}=0.001)$. Conversely, the score in this factor was positively correlated with the total score in the WHO-QoL-bref $(\mathrm{r}=0.353 ; \mathrm{p}=0.024)$ and the sub-score in its psychological domain $(r=0.446 ; \mathrm{p}=0.003)$.

Table 1. Pearson correlation coefficients between SSI-Del-Prette scores and a) burden (ZBI) and b) OoL (WHO0OL-bref) (N = 41)

\begin{tabular}{|c|c|c|c|c|c|c|c|}
\hline & & $\begin{array}{c}\text { Total score } \\
\text { SSI-Del-Prette }\end{array}$ & SSIF1 & SSI F2 & SSI F3 & SSIF4 & SSI F5 \\
\hline \multirow[t]{3}{*}{\begin{tabular}{|l} 
Burden score \\
\end{tabular}} & Pearson correlation coefficients & -.206 & .026 & -.109 & -.206 & -.080 & -.483 \\
\hline & Sig. (two-tailed) & .197 & .870 & .497 & .197 & .617 & .001 \\
\hline & $\mathrm{N}$ & 41 & 41 & 41 & 41 & 41 & 41 \\
\hline \multirow[t]{3}{*}{ WHO0OL-bref. total score } & Pearson correlation coefficients & .397 & .186 & .363 & .203 & .196 & .353 \\
\hline & Sig. (two-tailed) & .010 & .244 & .020 & .203 & .220 & .024 \\
\hline & $\mathrm{N}$ & 41 & 41 & 41 & 41 & 41 & 41 \\
\hline \multirow{3}{*}{$\begin{array}{l}\text { WH0Q0L-bref. physical } \\
\text { domain }\end{array}$} & Pearson correlation coefficients & .243 & .095 & .203 & .084 & .093 & .210 \\
\hline & Sig. (two-tailed) & .127 & .554 & .204 & .601 & .561 & .187 \\
\hline & $\mathrm{N}$ & 41 & 41 & 41 & 41 & 41 & 41 \\
\hline \multirow{3}{*}{$\begin{array}{l}\text { WHOOOL-bref. } \\
\text { psychological domain }\end{array}$} & Pearson correlation coefficients & .450 & .248 & .351 & .251 & .273 & .446 \\
\hline & Sig. (two-tailed) & .003 & .118 & .024 & .113 & .084 & .003 \\
\hline & $\mathrm{N}$ & 41 & 41 & 41 & 41 & 41 & 41 \\
\hline \multirow{3}{*}{$\begin{array}{l}\text { WHOQOL-bref. social } \\
\text { relations }\end{array}$} & Pearson correlation coefficients & .239 & .081 & .402 & .086 & .035 & .269 \\
\hline & Sig. (two-tailed) & .132 & .615 & .009 & .593 & .830 & .089 \\
\hline & $\mathrm{N}$ & 41 & 41 & 41 & 41 & 41 & 41 \\
\hline \multirow{3}{*}{$\begin{array}{l}\text { WHOOOL-bref. } \\
\text { environment }\end{array}$} & Pearson correlation coefficients & .408 & .188 & .308 & .321 & .222 & .241 \\
\hline & Sig. (two-tailed) & .008 & .240 & .050 & .041 & .162 & .129 \\
\hline & $\mathrm{N}$ & 41 & 41 & 41 & 41 & 41 & 41 \\
\hline
\end{tabular}

SSI: Social Skills Inventory; F1: coping and self-assertion with risk; F2: self-assertion in the expression of positive affect; F3: conversation and social confidence; F4: self-exposure to unknown people and new situations; $F 5$ : self-control of aggressiveness. 


\section{Discussion}

Our results show that family caregivers who have more elaborate repertoire of social skills tend to have a better quality of life and experience less burden. Factors 2 and 5 of the SSI-Del-Prette schedule are probably the ones that most contribute to the strength of these associations, due to the larger number of significant correlations observed between the scores in those two factors and the ZBI and WHO-QoL-bref scores. We hypothesize that self-assertion in the expression of positive affects (factor 2) and self-control of aggressiveness (factor 5) are skills that enable the caregiver to better cope with caregiving stress - without accumulating negative feelings - and, therefore, may help them experience a lesser degree of suffering while enduring this task. Nonetheless, it should be noted that depressive and anxiety symptoms decrease quality of life; these are very prevalent symptoms among caregivers, and may further modify their perception of burden and of his/her own personal skills. In addition, caregivers with better social skills may be more resilient against depressive/anxiety symptoms and therefore experience less burden and better quality of life.

The predominance of female caregivers reinforces the fact that there is a cultural conception of care while female function ${ }^{1,3}$. Moreover, ages ranged as described in the literature - caregivers are largely elderly. The fact that many did not have a formal employment is also in line with previous studies, ${ }^{4,14,15}$, and may be associated with full time dedication of these individuals to their relatives. The only data that differed from the typical caregiver profile ${ }^{4}$ were 'income' and 'education' (both were on average higher than what is reported in the literature).

We acknowledge the methodological limitations of our study but also its strengths: the sample size was relatively large and homogeneous. Besides, our findings are coherent and aligned with our working hypothesis. Given the limited information in this field, we believe that this study represents a relevant contribution for further research addressing variables that affect caregivers' wellbeing. The present set of data suggesting an association between social skills and caregiver's burden should be explored in larger and controlled studies, particularly taking into account the interaction of the former scores with those indicative of mental state changes, especially due to depression and anxiety. If replicated in larger samples and independent test groups, the present findings may indicate a possibility for interventional studies in family caregivers, aiming to enhance their social skills, improve their health and quality of care.

\section{References}

1. da Nova Cruz M, Cavalheiro HA. O impacto da doença de Alzheimer no cuidador. Psicol Estud. 2008;13(2):223-9.

2. Borges MF. Convivendo com Alzheimer: manual do cuidador. Available from: http://www.cuidardeidosos.com.br/wp-content/uploads/2008/04/ manual-do-cuidador-alzheimer.pdf. Accessed on: Nov. 17, 2016.

3. Neri AL, Sommerhalder C. Cuidar de idosos no contexto da família: questões psicológicas e sociais. Second edition. Campinas: Alínea; 2002. Chapter 1, As várias faces do cuidado e do bem-estar do cuidador. p. 9-63.

4. Faleiros DAM. Cuidadores de idosos com doença de Alzheimer: efeitos de grupos psico-educacionais e suporte domiciliar individualizado [dissertation]. São Carlos, BR; Universidade Federal de São Carlos; 2009.

5. Del Prette A, Del Prette ZAP. Teoria das Inteligências Múltiplas e treinamento de habilidades sociais. Doxa: Revista Paulista de Psicologia e Educação. 1999;5(1):51-63.

6. Del Prette A, Del Prette ZAP. Social Anxiety Disorders: From Theory to Practice. New York: Nova Science Publishers; 2013. Chapter 5, Social Skills Inventory (SSI-Del-Prette). p. 49-62.

7. Dornelles ARA. Uma intervenção psicoeducativa com cuidadores de idosos com demência. São Carlos [dissertation]. São Carlos, BR; Universidade Federal de São Carlos; 2010.

8. World Health Organization. WHOQOL: measuring quality of life. Available from: http://www.who.int/healthinfo/survey/whoqolqualityoflife/en/. Accessed on: 22nd Oct. 2015.

9. Organização Mundial da Saúde: Divisão de Saúde Mental - Grupo WHOQOL. Versão em português dos instrumentos de avaliação de qualidade de vida (WHOQOL). Available from: http://www.ufrgs.br/ psiquiatria/psiq/whoqol.html. Accessed on: Jan 10, 2013.

10. Pedroso B, Pilatti LA, Gutierrez GL, Picinin CT. Cálculo dos escores e estatística descritiva do WHOQOL-bref através do Microsoft Excel. Rev Bras Qual Vida. 2010;2(1):31-6.

11. Scazufca M. Brazilian version of the Burden Interview scale for the assessment of burden of care in carers of people with mental illnesses. Rev Bras Psiquiatr. 2002;24(1):12-7.

12. Taub A, Andreoli SB, Bertolucci PH. Dementia caregiver burden: reliability of the Brazilian version of the Zarit caregiver burden interview. Cad Saúde Pública. 2004;20(2):372-6.

13. Ricardo GD, Caldeira GV, Corso ACT. Prevalência de sobrepeso e obesidade e indicadores de adiposidade central em escolares de Santa Catarina, Brasil. Rev Bras Epidemiol. 2009;12(3):424-35.

14. Garrido R, Menezes PR. Impacto em cuidadores de idosos com demência atendidos em um serviço psicogeriátrico. Rev Saúde Pública. 2004;38(6):835-41.

15. Carretero S, Garcés J, Ródenas F, Sanjosé V. The informal caregiver's burden of dependent people: theory and empirical review. Arch Gerontol Geriatr. 2009;49(1):74-9. 